\title{
Perceptions, attitudes, and outcomes of human-snake encounters: A retrospective study of an online discussion community in Nigeria
}

\author{
OMOTOLA J. BABALOLA ${ }^{1,4}$, HENRY O. JEGEDE ${ }^{2, \vartheta}$, BAMIDELE N. OGUNRO ${ }^{3}$ \\ ${ }^{1}$ Faculty of Veterinary Medicine, University of Ibadan. Main Rd., Ibadan, Oyo State, Nigeria \\ ${ }^{2}$ Veterinary Teaching Hospital, University of Ilorin. P.M.B. 1515, Ilorin, Kwara State, Nigeria. Tel. +234-8038070602, `email: drlanrejeg@ gmail.com \\ ${ }^{3}$ Veterinary Teaching Hospital, University of Ibadan. Main Rd., Ibadan, Oyo State, Nigeria \\ ${ }^{4}$ Winthrop Veterinary Services. Osogbo, Osun State, Nigeria
}

Manuscript received: 11 April 2020. Revision accepted: 21 April 2020.

\begin{abstract}
Babalola OJ, Jegede HO, Ogundro BN. 2020. Perceptions, attitudes, and outcomes of human-snake encounters: A retrospective study of an online discussion community in Nigeria. Asian J Ethnobiol 3: 1-9. The internet is a valuable tool for obtaining data needed to study factors that hinder snake conservation, especially in resource-limited settings. There is a lack of peer-reviewed research on the use of online communities to examine factors contributing to undesirable human-snake conflicts in Nigeria. A 12-month dataset (August 2016-July 2017) on human-snake encounters shared on Nairaland ${ }^{\circledR}$ - a popular online community forum in Nigeria - was retrieved and analyzed. Morphological characteristics observed in the snake photographs posted on the platform were used for species identification. A total of 203 human-snake encounters were recorded from 32/37 States of Nigeria. Men ( $n=133)$ reported more humansnake encounters than women $(n=11)$, while 'reporters' of unspecified gender $(n=59)$ accounted for the rest. Most postings were from the southern part of Nigeria, with the highest number of postings from Lagos State $(n=34)$. Of the 24 snake species reported in the study, the African Rock Python was the most encountered. The months of May to July recorded the highest number of snake species reported by the respondents. 'Fear' and 'food' were the significant perceptions elicited by people during snake encounters. Humansnake conflicts resulted in snake deaths $(n=182)$ irrespective of snake venomosity. Only $1.0 \%(n=2)$ of the snakes were protected from harm. This study revealed that data from online community forums are helpful for retrospective analyses of the perceptions and outcomes of human-snake encounters, the output of which policymakers and conservationists may find helpful.
\end{abstract}

Keywords: Conservation, human-wildlife interface, nairaland, snakes, social media

\section{INTRODUCTION}

Wildlife populations and their habitats are declining at an alarming rate due to increasing human populations, climate change, and rapid urbanization (Kinnaird et al. 2003; Root et al. 2003; Carrete et al. 2007; Gusset et al. 2009). Although human conservation efforts and awareness have helped mitigate their decline, attitudes towards wildlife vary across different species and countries. Reptiles and amphibians are some of the taxa of the least researched, under-reported, and poorly documented worldwide (Shine and Bonnet 2000; Magle et al. 2012). Among reptiles, snakes are prime examples of wildlife that have been negatively affected by environmental degradation and increased urbanization (Seigel and Mullin 2009; Bonnet et al. 2016). The animals and their byproducts are helpful in medicine, religion, fashion, and the pet trade. Snakes provide ecosystem services in the form of predation (Alves and Filho 2007; Beaupre and Douglas 2009: 245; Herrel and van der Meijden 2014; Willson and Winne 2016).

Despite their importance, some species of snakes are under threat. A total of 185 snake species are listed in the IUCN red list of threatened species (IUCN 2013). This might result from various reasons - killed for food, out of fear, or for use in traditional medicine (Conant and Collins 1998; Soewu 2008; Pandey et al. 2016; IUCN 2018).
Conservation efforts have shown varying impacts across species and countries. These varied conservational impacts can be due to the perceived socio-political construction and power determining how allocations benefited the endangered species (Czech et al. 1998; Shine and Bonnet 2000; Marešová and Frynta 2008; Magle et al. 2012; de Pinho et al. 2014). Unlike other vertebrates, the conservation towards snakes is poor due to their negative perception of humans. Their unappealing skin coloration and the innate, protective, evolutionary adaptation of the human brain - which influences the basic human emotions, are some of the factors that contribute to the negative perception of snakes by man (Prokop and Fancovicova 2013; Prokop and Randler 2017; Prokop et al. 2018). There is poor awareness of snakes' conservation status, especially in developing countries, due to preliminary survey research (Pandey et al., 2016).

Local and international laws have been enacted to protect wildlife. However, these laws are not allencompassing in protecting snakes in their natural environments (Czech et al. 1998; Trouwborst et al. 2017). Cultural beliefs, especially myths and poor knowledge of the laws and snake classification based on venomously, are factors that hamper the protection of snake populations in the wild (Prokop et al., 2009; Ballouard et al. 2013). Fortunately, efforts have been made to create awareness of these animals via the use of documentaries, field trips, 
zoos, and wildlife parks (Morgan and Gramann 1989; Ballouard et al. 2012; Idowu and Morenikeji 2015; Pandey et al. 2016). However, zoos and wildlife parks conserve only a tiny population of snakes (Conway 2011). In developing countries, snake and human habitat are not usually delineated due to increasing urbanization, migration of people, and hunting practices (Bitanyi et al., 2012).

Recent advances in information technology are essential in conservation by providing easier access to information which can aid better decision making. The internet is beneficial in understanding factors hindering snake conservation. It can also enhance understanding of people's socio-cultural background and motivation without undue interference by researchers (Gunther and Jeremy 2002; Arts et al. 2015). Social media, especially online communities, have been used in creating awareness of the reintroduction of fish and amphibians (Jachowski et al., 2016). However, there is a lack of peer-reviewed research involving online communities in understanding the perceptions, attitudes, and outcomes of snake-human interactions, especially in developing countries like Nigeria. This study hypothesizes that social media - online communities - can be used as a medium to explore the perceptions, attitudes, and outcomes of human-snake encounters in Nigeria. In addition, we hypothesized that human-snake encounters as posted on popular online forums reflect the actual nature and relative proportions of such encounters in the respective locations from which the posts were made. This study aims to evaluate the engagement of an online discussion community in snake conservation and management in Nigeria. In this paper, our objectives include: assessing the species and the conservation statuses of snakes posted on an online discussion community website in Nigeria, evaluating the geographical and monthly distribution of snakes reported in an online discussion community website in Nigeria, determining the perceptions, attitudes, and outcomes of human-snake encounters as reported in an online discussion community website in Nigeria, as well as evaluating the sex characteristics and location of respondents that reported the human-snake encounters online on a discussion community website in Nigeria.

\section{MATERIALS AND METHODS}

\section{Study site}

Nairaland ${ }^{\circledR}$ was the primary website used for this study. It is a highly rated website in Nigeria, with more than one million registered members engaged in various topics (Osewa 2018; Alexa 2018). Google ${ }^{\mathrm{TM}}$ was also used to trawl data linked to the website. The data analyzed for this study were not password-protected or prohibited by the site's policy. Also, the website members were anonymous (Eysenbach and Till 2001; Walther 2002; Gunther and Jeremy 2002; Herron et al. 2011; Harriman and Patel 2014).

\section{Search terms}

The search terms used ensured that the search was sensitive to capture all important details. The search terms used included: (i) Nairaland ${ }^{\circledR}$ : "snake(s)"; "snakes+2016", "snakes AND 2016. (ii) Google ${ }^{\mathrm{TM}}$ : "nairaland AND snake AND 2016", snakes AND nairaland AND 2017.

The search was conducted retrospectively, spanning from August 2016 to July 2017. July 2017 was chosen as the end date of the study to coincide with the world snake day on 16 July, an occasion that highlights the need for snake conservation (Days of the week 2019). All the sections, images, and topics on Nairaland ${ }^{\circledR}$ were selected for review and analysis via the search filters.

\section{Inclusion and exclusion criteria}

We selected data based on the following inclusion criteria: snakes in Nigeria, pictures of the snakes being killed, snakes reportedly killed by Nigerians, the topics are written in English while the exclusion criteria include documentaries on snakes, snakes reported outside the country, no pictures of snakes, other sites not primarily Nairaland ${ }^{\circledR}$, double entries by different profiles or same profile and snakes in established snake markets. Some data were classified as unknown/ unspecified/ uncertain if the respondents did not include their gender on the site or the snakes could not be identified using standard procedures by the authors.

Snakes displayed for sale in established markets were omitted because they could introduce sampling bias. Also, the location of the markets would be difficult to prove. The profile's characteristics that met the inclusion criteria were checked, while the other areas of interest were iteratively analyzed to ensure data validity.

\section{Snake species identification and data analysis}

We identified snake species based on morphological characteristics and appearance. We verified the conservation statuses of each snake species via relevant scientific literature and databases (Wallach et al. 2014; IUCN 2019; Uetz et al. 2017).

Data were collected and sorted with Microsoft Excel. The final dataset was transferred to SPSS 20 statistical computer software package. Description of the data was by frequency tables and charts. Multivariate logistic regression analysis was used to test if any of the following variables (sex of respondents, venomously of snakes, circumstance of encounter, taxonomic class of snake, and geopolitical zone from which posts were identified) were predictors of outcomes of human-snake encounters. Respondents' perceptions towards snakes (fear, food, etc.) and snakehuman interactions were measured by assessing the overall tone of the post. For example, one of the respondents used to write:

"How this snake crawled into our room, no one can possibly explain. My roommate was lucky. Cos he was trying to open the wardrobe and when he saw the snake he froze like a statue and all he could do was to keep shouting Jesus! ...Cos Even me no get mind, we were lucky cos a guy from another room helped us kill it...." 
To determine predictors for the outcome of humansnake encounters, States were grouped into the 6 geopolitical zones of Nigeria. "Sold" and "captured" were collapsed into one category "spared"; "uncertain outcome" and "found dead" were excluded from the analysis making three possible outcomes viz: "killed," "eaten," and "spared." Fisher exact or Chi-square tests were carried out on the data using Epi Info 7.2.0. A P-value less than 0.05 was considered statistically significant.

\section{RESULTS AND DISCUSSION}

\section{Sex characteristics of the respondents that reported} snake encounters on Nairaland ${ }^{\circledR}$

The final sample consisted of 203 respondents. There were 133 men $(65.5 \%), 11$ women $(5.4 \%)$, and 59 respondents with unspecified gender $(29.1 \%)$ that reported the human-snake encounters online.

\section{Number of snakes and snake posts reported on} Nairaland ${ }^{\circledR}$ per state

A total of 203 snakes were reported in 202 separate encounters that encompassed almost all the states in Nigeria $(n=31)$. Of the total snakes reported, $16.7 \%$ were from Lagos State $(n=34)$ (Fig. 1).

The family Pythonidae accounted for $36.5 \%$ of the snakes encountered $(n=74)$ while $12.3 \%(n=25)$ were in Colubridae, $20.2 \%(n=41)$ in Elapidae, $19.7 \% \quad(n=40)$ in Lamprophiidae, $9.9 \%(\mathrm{n}=20)$ in Viperidae, and $1.5 \%(\mathrm{n}=3)$ uncertain (Fig. 2). The non-venomous snakes $(n=136)$ accounted for $67.0 \%$ of the snakes encountered, while $31.5 \%$ of the snakes were venomous $(n=64)$, and $1.5 \%$ of the snakes could not be categorized $(n=3)$. The conservation status of the African Rock Python was 'near threatened' while the other snake species were of the 'least concern' status (Table 1$)$. The months of May $(n=35)$, June $(n=38)$, and July $(n=27)$ recorded the highest number of snake encounters reported by Nairaland ${ }^{\circledR}$ users (Fig. 3).

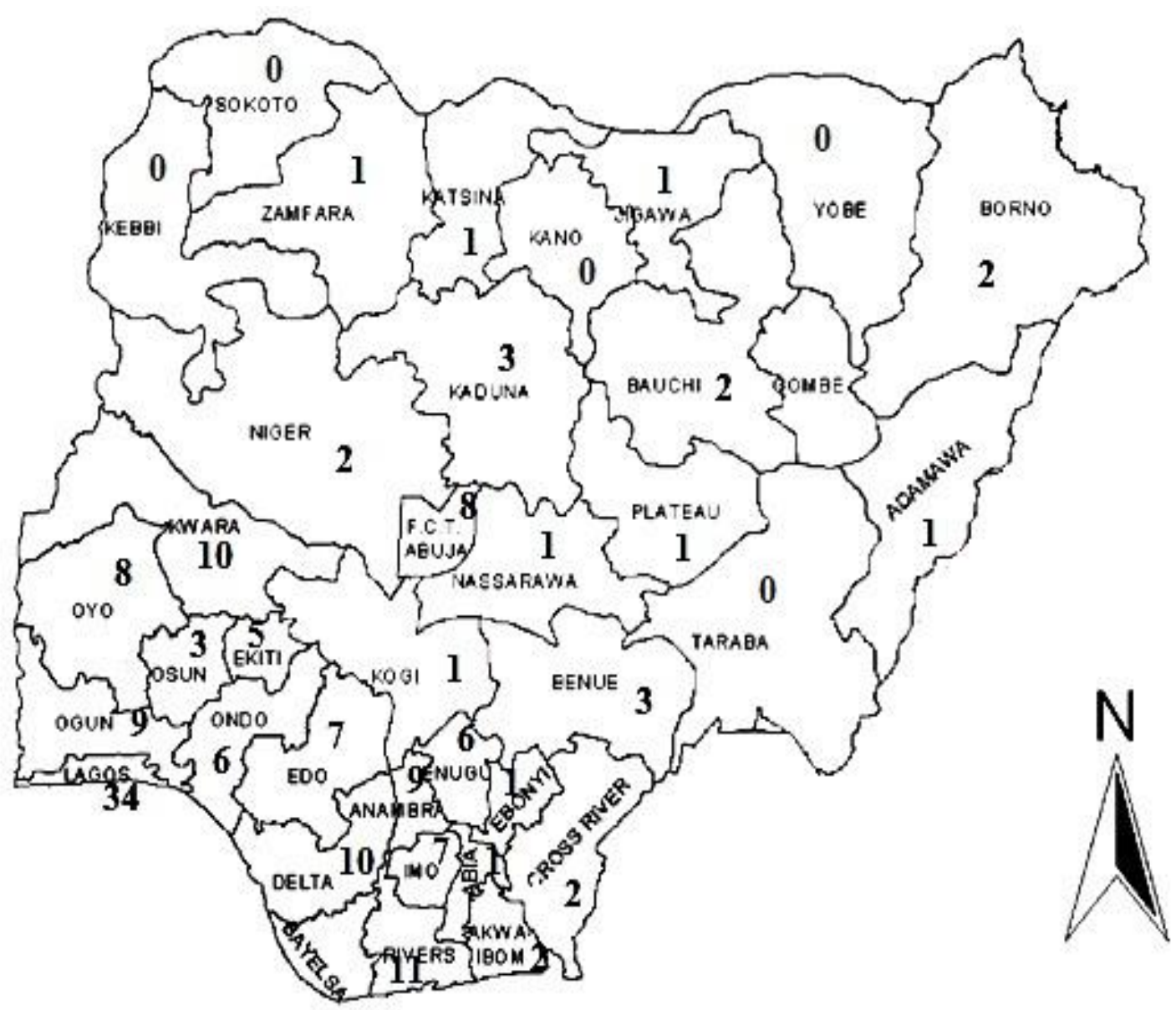

100

0

400

800 Kilometers

Figure 1. Map of Nigeria showing the distribution of snake classes by state encountered and posted on Nairaland ${ }^{\circledR}$ between August 2016-July 2017. 
Table 1. Identity, frequency, and conservation status of snakes encountered and posted on Nairaland ${ }^{\circledR}$ between August 2016-July 2017 in order of frequency.

\begin{tabular}{|c|c|c|c|}
\hline Common name & Scientific name & $\begin{array}{l}\text { Number of } \\
\text { snakes (\%) }\end{array}$ & $\begin{array}{l}\text { Conservation } \\
\text { status }\end{array}$ \\
\hline African Rock Python & Python sebae (Gmelin, 1789) & $55(27.1)$ & Near threatened \\
\hline House snakes & Boaedon spp. (Boulenger, 1893) & $27(13.3)$ & Least Concern \\
\hline Black-necked spitting cobra & Naja nigricollis (Reinhardt, 1843) & $21(10.3)$ & Least Concern \\
\hline Royal python & Python regius (Shaw, 1802) & $19(9.4)$ & Least Concern \\
\hline Bush snakes & Philothamnus spp. (Smith, 1840) & $12(5.9)$ & Least Concern \\
\hline Forest cobra & Naja melanoleuca (Hallowell, 1857) & $12(5.9)$ & Least Concern \\
\hline Gaboon viper & Bitis gabonica (Duméril, Bibron and Duméril, 1854) & $8(3.9)$ & Least Concern \\
\hline Puff adder & Bitis arietans (Merrem, 1820) & $7(3.4)$ & Least Concern \\
\hline Olive Grass Racer & Psammophis phillipsii (Hallowell, 1844) & $7(3.4)$ & Least Concern \\
\hline African Garter Snake & Elapsoidea semiannulata moebiusi (Broadley, 1971) & $6(3.0)$ & Least Concern \\
\hline Common egg eater & Dasypeltis scabra (Linnaeus, 1758) & $4(2.0)$ & Least Concern \\
\hline African night adder & Causus rhombeatus (Lichtenstein, 1823) & $3(1.5)$ & Least Concern \\
\hline Striped Sand Snake & Psammophis sibilans (Linnaeus, 1758) & $3(1.5)$ & - \\
\hline Uncertain & Uncertain & $3(1.5)$ & - \\
\hline Katian Spitting cobra & Naja katiensis (Angel, 1922) & $2(1.0)$ & Least Concern \\
\hline Elegant sand racer & Psammophis elegans (Shaw, 1802) & $2(1.0)$ & Least Concern \\
\hline Smith's African Water Snake & Grayia smithii (Leach, 1818) & $2(1.0)$ & Least Concern \\
\hline Forest file snake & Mehelya poensis (Smith, 1849) & $2(1)$ & Least Concern \\
\hline Blandings tree snake & Toxicodryas blandingii (Hallowell, 1844) & $2(1.0)$ & - \\
\hline West African Herald Snake & Crotaphopeltis hippocrepis (Reinhardt, 1843) & $1(0.5)$ & Least Concern \\
\hline West African Night Adder & Causus maculatus (Hallowell, 1842) & $1(0.5)$ & Least Concern \\
\hline Rufous Beaked Snake & Rhamphiophis oxyrhynchus (Reinhardt, 1843) & $1(0.5)$ & Least Concern \\
\hline West African carpet Viper & Echis ocellatus (Stemmler, 1970) & $1(0.5)$ & Least Concern \\
\hline Striped swamp snake & Dromophis praeornatus (Peters, 1869) & $1(0.5)$ & Least Concern \\
\hline \multirow[t]{2}{*}{ Slender blind snake } & Myriopholis narirostris (Peters, 1867) & $1(0.5)$ & Least Concern \\
\hline & Total & 203(100.0) & \\
\hline
\end{tabular}

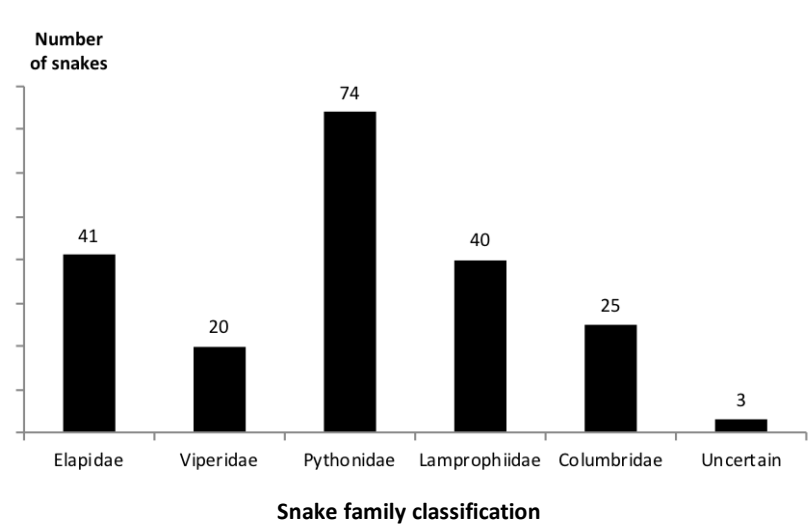

Figure 2. Family classification of snakes posted on Nairaland ${ }^{\circledR}$ between August 2016-July 2017

\section{Places, perceptions, and outcomes of human-snake encounters}

Most online posts reported an increased frequency of human-snake encounters at residential areas $(n=118)$ while farms/forests $(n=34)$, public places $(n=19)$, and uncertain locations $(n=32)$ accounted for the rest (Fig. 4). Snake encounters with humans elicited fear $(n=112)$ in $55.2 \%$ of the online posts, while $22.1 \%$ of the snakes $(n=45)$ encountered were killed for food. Conservation $(n=2)$ and display $(n=3)$ accounted for $1.0 \%$ and $1.5 \%$ of the reports respectively. There were 41 reports $(20.2 \%)$ classified as unknown because the perceptions of snake encounters with humans could not be deduced from the posts (Fig. 5). Display in this context refers to the use of these snakes to attract pedestrians by snake charmers

Human-snake encounters killed the snakes encountered by humans $(n=156)$ while man ate 26 snakes. Other outcomes included being captured $(n=8)$, uncertain $(n=8)$, sold $(n=1)$, found dead $(n=3)$, and snake being left alone $(n=1)$. Fisher's exact test showed no significant association between danger posed by snake regardless of venomously and outcome of the snake-human encounter $(\mathrm{OR}=0.73$, $\mathrm{CI}=0.33-1.62, P=0.56$ ). Venomous snakes were not more likely to be feared than non-venomous ones.

Multivariate logistic regression analysis revealed that none of the variables (sex of respondents, venomously, a circumstance of encounter, taxonomic class, and geopolitical zones from which the posts were identified) included in the model were predictors for the outcome human-snake encounters at $90 \%$ or $95 \%$ confidence intervals. 


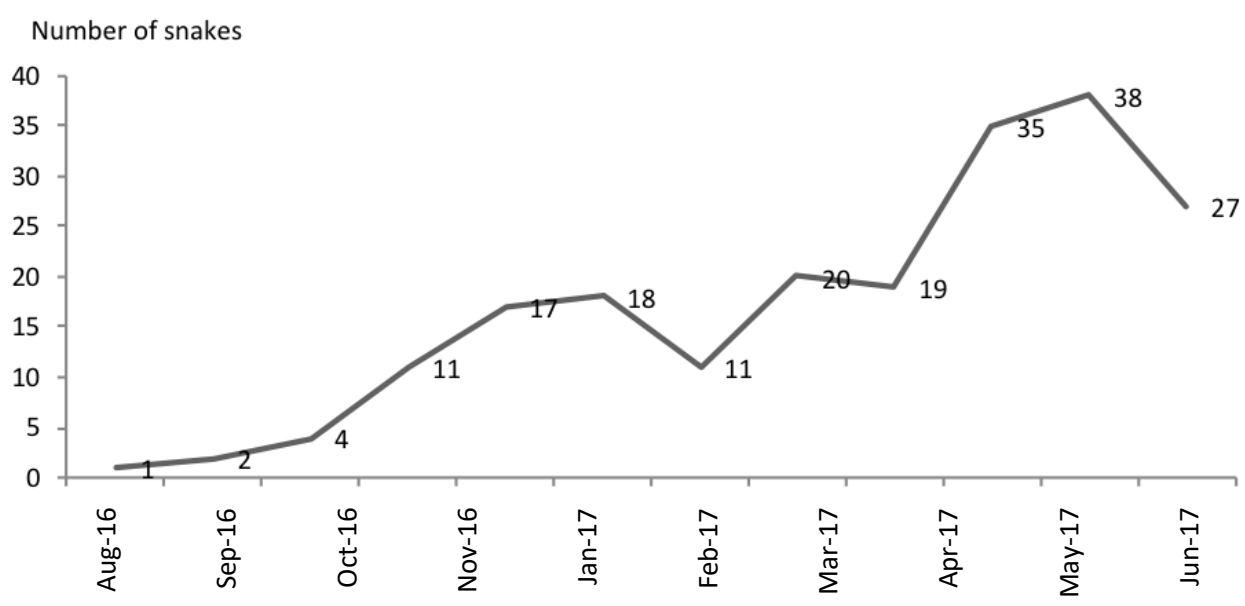

Figure 3. Monthly distributions of different individual snakes encountered as posted on Nairaland® between August 2016-July 2017

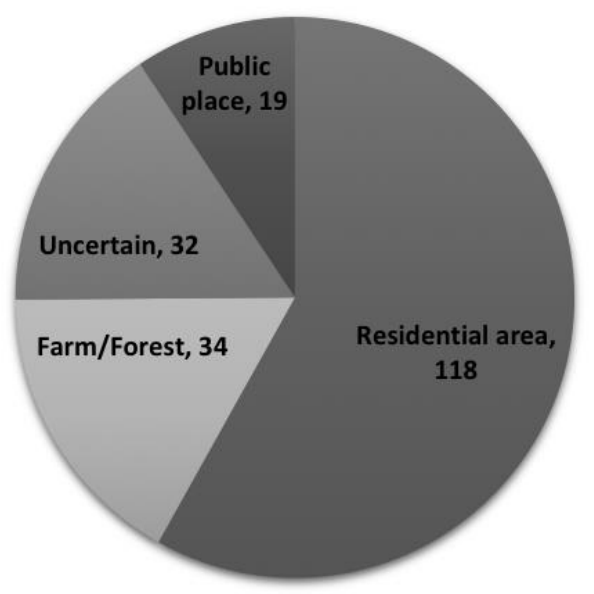

Figure 4. Site of human-snake encounters as posted on Nairaland ${ }^{\circledR}$ between August 2016-July 2017

\section{Discussion}

Conservation of animals in their natural habitat is an urgent issue that requires numerous interventions. The advent of new information technologies such as the internet serves as another opportunity to harness its advantages towards animal conservation. Some authors advocate the internet as a new interface in wildlife management, ecotourism, and collaboration among numerous stakeholders engaged in conservation (Prendergast et al. 1999; Yasuda and Kawakami 2002; Huettmann 2005; Lai and Shafer 2005; Gusset and Dick 2010). It has also been used to understand different perspectives and funding of animal conservation (Rastogi et al., 2013; Verissimo et al., 2017). Therefore, the internet provides a new avenue where the perceptions and attitudes of people toward conservation can be studied.

Snakes are good examples of poorly documented and understudied wildlife and benefit poorly from allocated resources that will aid their conservation in the wild. Numerous studies have been conducted to unravel the

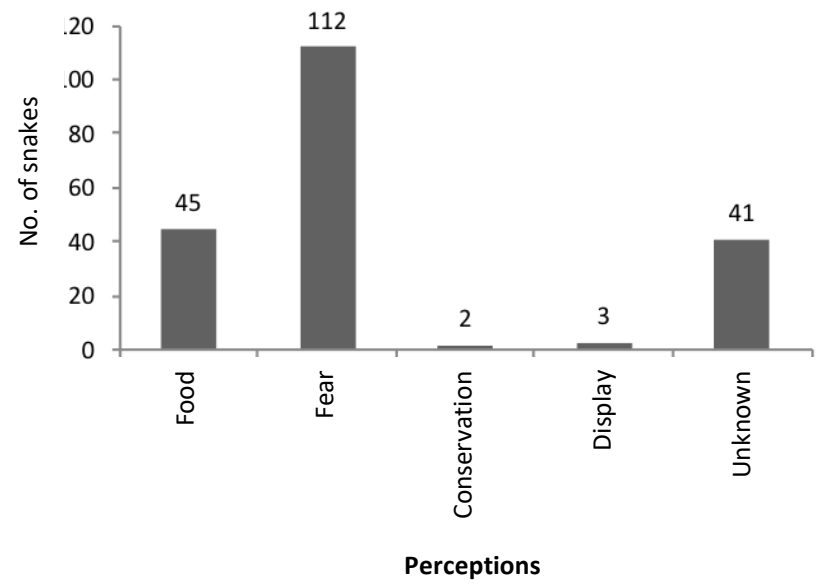

Figure 5. Perceptions towards snakes as posted on Nairaland ${ }^{\circledR}$ between August 2016-July 2017

perceptions towards human-wildlife conflict (Treves and Karanth 2003; Lucherini and Merino 2008; Inskip and Zimmermann 2009). A study by Miranda et al. (2016) used internet videos to examine the ecology of the humananaconda conflict. Their findings revealed another dimension of human-wildlife conflicts - anacondas were anticipatorily killed because humans negatively perceived them to be dangerous. Apart from this study, there is a scarcity of information on the internet to investigate the conflict of humans towards snakes, especially in developing countries like Nigeria. The choice of Nairaland ${ }^{\circledR}$ as the website for this study was the ease of access as a public forum in Nigeria. Nairaland ${ }^{\circledR}$ has been used to understand Nigerian pidgin's linguistic evolution in the digital world and public perceptions about some significant issues in Nigeria (Heyd and Mair 2014; Chiluwa and Odebunmi 2016). Therefore, this study used Nairaland ${ }^{\circledR}$ as a platform to understand the perceptions, attitudes, and outcomes of human-snake encounters. 
Almost all the States in Nigeria were represented in the study via the snake posts uploaded online. This indicates that Nairaland $\AA$ is a widely accessible forum in Nigeria. This agrees with Chiluwa and Odebunmi (2016)'s study, which revealed that the site serves as a meeting place for people in Nigeria. Therefore, Nairaland $®$ can be a platform for delivering educational interventions on conservations to its users.

We found out that the snakes encountered in this study were reported from almost all parts of Nigeria. This indicates that the geographical distribution of snakes was all over Nigeria (Luiselli 2001; Molesworth et al. 2003; Akani et al. 2013). Therefore, comprehensive conservational interventions need to be carried out all over the country to protect snakes in their natural habitats. The online community website, Nairaland $\AA$, could serve as a valuable data source for mapping tools such as HerpMapper and iNaturalist, which could potentially benefit the conservation of snakes by providing new and readily accessible information on the distribution of different snake species in Nigeria.

Twenty-four snakes out of 125 species (19.2\%) found in Nigeria were reported in our study (Uetz et al., 2017). The snake species encountered in this study were classified into the Colubridae, Elapidae, Viperidae, Pythonidae, and Lamprophiidae families. Some of these families were also encountered in the study by Akani et al. (2013). The distribution pattern indicates that the families are ubiquitous and represent various snake species in Nigeria.

The months of May to July recorded the highest distribution of snakes reported on Nairaland®. This distribution pattern agrees with the findings of Akani et al. (2013) and Sani et al. (2013), who reported that April to July were the months that witnessed high snake and human activities. The high incidence of human-snake encounters in these months might result from heavy rains in the rainy season that flood the habitats of these snakes, which drives them to seek shelter in warmer human residences. It could also be because the number of people accessing and posting to Nairaland peaks in May-July.

The African Rock Python, Python sebae, was the snake species encountered most in the study. It was killed mainly as a result of its intrinsic value as bushmeat. This agrees with the research findings of Mallon et al. (2015), which showed that pythons were widely hunted for consumption, traditional, and commercial purposes. This implies that bush meat and free international wildlife trade significant barriers to conservation in developing countries.

The conservation statuses of the snake species reported in the study varied from" least concerned" to "near threatened" according to the IUCN classification. However, the study of Reading et al. (2010) indicated that some of the snake species encountered in our research - the Gaboon Viper, Bitis gabonica, and the Royal Python, Python regius - have been undergoing some population decline in Nigeria. This shows that our knowledge of the conservation status of snake species is doubtful. Even though the IUCN lists only one species as near threatened, there could be a high chance other snake species are also of conservation concern. Most snake species are listed as 'Data Deficient' by the IUCN, and many species are not listed at all (IUCN 2019). Therefore, further studies should be conducted to ascertain the accurate population statuses of each snake species in the wild to designate and enact the correct conservation status and laws, respectively, thereby protecting the snake species.

In our present study, females reported fewer humansnake encounters online. Recent studies showed that females were less tolerant of snakes than males (Pinheiro et al. 2016; Liordos et al. 2017, 2018). This might be due to the complex biological and evolutionary roles that natural selection play in ensuring that females with lower bodily conditions have increased self-protection systems - which is manifested as fear - to combat potential physical dangers (Røskaft et al. 2003; Prokop and Fančovičová, 2010, 2013). Conversely, males reported a higher number of humansnake encounters online. Men's perception could explain that displaying dead snakes online will be viable means of showing off and boosting their masculine egos and online profiles to increase their physical attractiveness to the female members of the online discussion community. Escasa et al. (2010)'s study of male attractiveness rankings in a small-scale Amazonian society showed that females were attracted to male traits such as status, gallantry, and hunting ability. However, the finding of this study cannot be generalized to other study settings, especially in a complex and ever-changing world.

Our study also revealed that the most frequent site of human-snake encounters was in residential areas. This agrees with Purkayastha et al.'s (2011) finding that some snake species such as Lycodon aulicus were found in residential areas. Apart from residential areas, our study also revealed that farms, forests, and public places were the other locations of high human-snake encounters. The studies of Whitaker and Shine (1999) and Carter et al. (2014) revealed that agricultural lands and recreational parks increased the chances of human encounters with the Australian brown snakes, Pseudonaja textilis, and copperhead snakes. Increased destruction and degradation of the snake's natural habitats, increased human population growth, and rapid urbanization is some of the reasons that could explain the above-described findings.

We found out that the perceptions of humans to snakes elicited fear regardless of their venomous nature. This agrees with the works of Alves et al. (2014) and Pandey et al. (2016), who found that fear was a natural cause that hindered snake conservation. This might result from poor awareness in distinguishing venomous and non-venomous snakes. However, Corbett et al. (2005) found that most people can correctly identify local venomous snakes. The sampling of interested people at a local snake street fair imparted sampling bias that might have restricted the generalization of the study findings to the entire population. Also, our study showed that venomous snakes were not more likely to be feared than non-venomous snakes. Local folklore and reported harms - mortalities may accentuate the negative perception of snakes. However, some traditional beliefs might positively protect some snake species from harm. A study by Rim-Rukeh et al. (2013) revealed that the reverence of pythons in some areas 
of Delta State, Nigeria boosted their local populations within those communities. Similarly, Sasaki et al. (2010) recommended the preservation of the vanishing Japanese traditional beliefs - the adoration of snakes as gods - very critical to the conservation of snakes in Japan. Nevertheless, most snakes encountered in this study were killed out of fear and food. Therefore, indiscriminate killing of snakes without proper awareness of their importance might lead to their decline in the world, which might negatively affect the balance of the ecosystem.

It is alarming that only a few snakes were captured alive in our study. Most respondents reported and posted killed snakes to get placement in a more prominent section - front page - of the online discussion community forum; this means that Nigerians' attitudes towards conservation are relatively weak. Therefore, conservationists and other significant stakeholders should make more efforts to raise awareness of the need to conserve wild herpetofauna among the Nigerian people.

A significant limitation of this study is the nonrepresentativeness of the samples. The snakes reported in our study are mainly those found in residential areas or those with dietary value (pythons). Although other snakes were not reported, it does not imply the absence of these snakes in Nigeria. Still, it suggests their absence, low relative abundance, low detection probability in residential areas, or lack of dietary value. For instance, unreported species like Calabaria and blind snakes are burrowing forest snakes rarely encountered. At the same time, Dendroaspis (Tree Mambas) and Dispholidus (Boomslangs) are arboreal dwellers found mostly atop palm trees and very tall trees. Even though some snake species, such as the Mambas and the Boomslangs, are not hard to see, the photographs of these snake species are scarce because they are fast-moving and dangerous. This limits the studying of snakes from data taken from online communities because some important snake species might be excluded. However, because people's perceptions of snakes were examined, the accurate representation of the snake populations in the wild did not influence the study's validity.

Another limitation of the study is that the community studied is an online community. This limits the data to only internet savvy and active members of the Nairaland® forum (as this was the only site checked). The study is also limited to people who own a device capable of taking a photo: a camera, smartphone, or other phones with a camera, and those that have the financial ability to purchase and access the data subscription needed to upload a photo. Although those in rural areas have an increased chance of encountering these snakes, the poor internet coverage and the low socioeconomic statuses of those living in the rural areas of Nigeria might hinder the taking and uploading of pictures of these snakes.

The inclusion criteria used during the methodology aspect were written in English. This biased the results towards Nigerian users of this online discussion community forum with higher levels of education (Hargittai 2007, 2010; Duggan and Brenner 2013). However, because the scope of this study was limited to the internet, this might not affect its validity. Perceptions toward snakes were measured by assessing the overall tone of the posts. This might introduce a measurement bias due to the subjective nature of interpreting the posts. However, the uploaded snake photographs, the locations, and the outcomes of the human-snake encounters assisted in minimizing this bias.

This study was the first to our knowledge to retrospectively use social media to examine the perceptions and outcomes of human-snake encounters in a developing country. Policymakers and conservationists should consider social media, especially online discussion forums, as an avenue to deliver targeted educational interventions. The use of data from social media could aid in changing the perceptions and attitudes of these particular sets of internetoriented Nigerian populations and educating them on the need to conserve snakes and other wildlife.

\section{ACKNOWLEDGEMENTS}

The authors would like to acknowledge the input of Babasola O. Olugasa of the Department of Veterinary Public Health and Preventive Medicine, University of Ibadan, Ibadan, for his information into the GIS design of the map of Nigeria. The contributions of Victor Ladipo of the $21^{\text {st }}$ Century Environmental Consultants Inc, Calgary, in making the manuscript better in terms of grammar and clarity of words were appreciated. We would also like to appreciate the website users where the data used for this paper were obtained.

\section{REFERENCES}

Akani GC, Ebere N, Franco D, Eniang EA, Petrozzi F, Politano E, Luiselli L. 2013. Correlation between annual activity patterns of venomous snakes and rural people in the Niger Delta, southern Nigeria. J Venomous Animals and Toxins including. Tropic Dis 19: 2. DOI: 10.1186/1678-9199-19-2.

Alves RR, Silva VN, Trovão DM, Oliveira JV, Mourão JS, Dias TL, Alves AG, Lucena RF, Barboza RR, Montenegro PF, Vieira WL. 2014. Students' attitudes toward and knowledge about snakes in the semiarid region of Northeastern Brazil. J Ethnobiol and Ethnomedicine 10: 30. DOI: 10.1186/1746-4269-10-30.

Alves RRN, Filho GAP. 2007. Commercialization and use of snakes in North and Northeastern Brazil: implications for conservation and management. Biodiv Conserv 16: 969-985. DOI: 10.1007/978-14020-6320-6 9.

Arts K, Van Der Wal R, Adams WM. 2015. Digital technology and the conservation of nature. Ambio 44: 661-673. DOI: 10.1007/s13280015-0705-1.

Ballouard JM, Ajtic R, Balint H, Brito JC, Crnobrnja-Isailovic J, Desmonts D, Elmouden EH, Erdogan M, Feriche M, Pleguezuelos JM, Prokop P. 2013. Schoolchildren and one of the most unpopular animals: are they ready to protect snakes?. Anthrozoös 26: 93-109. DOI: 10.2752/175303713X13534238631560.

Ballouard JM, Provost G, Barré D, Bonnet X. 2012. Influence of a field trip on the attitude of schoolchildren toward unpopular organisms: an experience with snakes. J Herpetol 46: 423-428. DOI: 10.1670/11118.

Beaupre SJ, Douglas LE. 2009. Snakes as indicators and monitors of ecosystem properties. In: Seigel RA, Mullin SJ (eds). Snakes, Ecology, and Conservation. Cornell University Press, Ithaca, New York, USA.

Bitanyi S, Nesje M, Kusiluka LJ, Chenyambuga SW, Kaltenborn BP. 2012. Awareness and perceptions of local people about wildlife 
hunting in western Serengeti communities. Trop Conserv Sci 5: 208224. DOI: $10.1177 / 194008291200500209$.

Bonnet X, Lecq S, Lassay JL, Ballouard JM, Barbraud C, Souchet J, Mullin SJ, Provost G. 2016. Forest management bolsters native snake populations in urban parks. Biol Conserv 193: 1-8. DOI: 10.1016/j.biocon.2015.11.001.

Carrete M, Grande JM, Tella JL, Sánchez-Zapata JA, Donázar JA, DíazDelgado R, Romo A. 2007. Habitat, human pressure, and social behaviour: partialling out factors affecting large-scale territory extinction in an endangered vulture. Biol Conserv 136: 143-154. DOI: 10.1016/j.biocon.2006.11.025.

Carter ET, Attum O, Eads BC, Hoffman AS, Kingsbury BA. 2014. Reducing the potential for human-snake encounters in a recreational park. Human-Wildlife Interactions 8: 158-167. DOI: 10.26077/ggt7vr34.

Chiluwa I, Odebunmi A. 2016. On terrorist attacks in Nigeria: stance and engagement in conversations on Nairaland. Commun Public 1: 91109. DOI: $10.1177 / 2057047315624926$.

Conant R, Collins JT. 1998. A field guide to reptiles \& amphibians: eastern and central North America. Vol. 12. Houghton Mifflin Harcourt. 12: 11-12.

Conway WG. 2011. Buying time for wild animals with zoos. Zoo Biol 30 1-8. DOI: $10.1002 /$ zoo.20352.

Cooper C, Dickinson J, Phillips T, Bonney R. 2007. Citizen science as a tool for conservation in residential ecosystems. Ecol Soc 12: 11. DOI: 10.5751/ES-02197-120211.

Corbett SW, Anderson B, Nelson B, Bush S, Hayes WK, Cardwell MD. 2005. Most lay people can correctly identify indigenous venomous snakes. The Am J Emergency Med 23: 759-762. DOI: 10.1016/j.ajem.2005.03.008.

Czech B, Krausman PR, Borkhataria R. 1998. Social construction, political power, and the allocation of benefits to endangered species. Conserv Biol 12: 1103-1112. DOI: $10.1046 / j .1523-$ 1739.1998.97253.x.

De Pinho JR, Grilo C, Boone RB, Galvin KA, Snodgrass JG. 2014 Influence of aesthetic appreciation of wildlife species on attitudes towards their conservation in Kenyan agropastoralist communities. PloS ONE 9 (2): e88842. DOI: 10.1371/journal.pone.0088842.

Duggan M, Brenner J. 2013. The demographics of social media users, 2012. (Vol.14). Washington, DC: Pew Research Center's Internet \& American Life Project.

Escasa M, Gray PB, Patton JQ. 2010. Male traits associated with attractiveness in Conambo, Ecuador. Evolution and Human Behavior 31: 193-200. DOI: DOI 10.1016/j.evolhumbehav.2009.09.008.

Eysenbach G, Till JE. 2001. Ethical issues in qualitative research on internet communities. British Medical Journal 323: 1103-1105. DOI: 10.1136/bmj.323.7321.1103.

Gunther E, Jeremy W. 2002. Using the Internet for surveys and health research. J Med Internet Res 4 (2): e13. DOI: 10.2196/jmir.4.2.e13.

Gusset M, Dick G. 2010. 'Building a Future for Wildlife'? Evaluating the contribution of the world zoo and aquarium community to in situ conservation. Intl Zoo Yearbook 44: 83-191. DOI: 10.1111/j.17481090.2009.00101.x.

Gusset M, Swarner MJ, Mponwane L, Keletile K, Mcnutt JW. 2009. Human-wildlife conflict in northern Botswana: livestock predation by endangered African wild dog Lycaon pictus and other carnivores. Oryx 43: 67-72. DOI: 10.1017/S0030605308990475.

Hargittai E. 2007. Whose space? Differences among users and non-users of social network sites. J Computer-mediated Commun 13: 276-297. DOI: 10.1111/j.1083-6101.2007.00396.x.

Hargittai E. 2010. Digital na (t) lives? Variation in internet skills and uses among members of the "net generation." Sociol Inquiry 80: 92-113. DOI: 10.1111/j.1475-682X.2009.00317.x.

Harriman S, Patel J. 2014. The ethics and editorial challenges of internetbased research. BMC Med 12: 124. DOI: 10.1186/PREACCEPT1753356481135356.

Herrel A, Van Der Meijden A. 2014. An analysis of the live reptile and amphibian trade in the USA compared to the global trade in endangered species. Herpetol J 24: 103-110.

Herron M, Sinclair M, Kernohan WG, Stockdale J. 2011. Ethical issues in undertaking internet research of user-generated content: a review of the literature. Evid Based Midwifery 9: 9-15.

Heyd T, Mair C. 2014. From vernacular to the digital ethnolinguistic repertoire: the case of Nigerian Pidgin. Indexing Authenticity: Sociolinguistic Perspectives. de Gruyter, Berlin.
Huettmann F. 2005. Databases and science-based management in the context of wildlife and habitat: toward a certified ISO standard for objective decision-making for the global community by using the internet. J Wildl Manag 69: 466-472. DOI: 10.2193/0022541X(2005)069[0466:DASMIT]2.0.CO;2.

Idowu MA, Morenikeji OA. 2015. Wild Fauna Conservation in Nigeria. Environ Nat Resour Res 5 (3): 98-108. DOI: 10.5539/enrr.v5n3p98.

Inskip C, Zimmermann A. 2009. Human-felid conflict: a review of patterns and priorities worldwide. Oryx 43: 18-34. DOI: 10.1017/S003060530899030X.

International Union for the Conservation of Nature (IUCN). 2013. Year of the Snake: an online reference. https://www.iucn.org/content/yearsnake.

IUCN [International Union for the Conservation of Nature]. 2018. The IUCN Red List of Threatened Species, 2018. https://www.iucnredlist.org/search?page=2.

IUCN [International Union for the Conservation of Nature]. 2019. The IUCN Red List of Threatened Species, Version 2019-1. https://www.iucnredlist.org/.

Jachowski DS, Millspaugh JJ, Angermeier PL, Slotow R. 2016. Reintroduction of Fish and Wildlife Populations. University of California Press, Berkeley, California, USA. DOI: $10.1525 / 9780520960381$.

Kinnaird MF, Sanderson EW, O'Brien TG, Wibisono HT, Woolmer G. 2003. Deforestation trends in a tropical landscape and implications for endangered large mammals. Conserv Biol 17: 245-257. DOI: 10.1046/j.1523-1739.2003.02040.x.

Lai PH, Shafer S. 2005. Marketing ecotourism through the Internet: an evaluation of selected ecolodges in Latin America and the Caribbean. J Ecotourism 4: 143-160. DOI: 10.1080/JET.v4.i3.pg143.

Liordos V, Kontsiotis VJ, Anastasiadou M, Karavasias E. 2017. Effects of attitudes and demography on public support for endangered species conservation. Sci Total Environ 595: 25-34. DOI: 10.1016/j.scitotenv.2017.03.241.

Liordos V, Kontsiotis VJ, Kokoris S, Pimenidou M. 2018. The two faces of Janus, or the dual-mode of public attitudes towards snakes. Sci Total Environ 621: 670-678. DOI: 10.1016/j.scitotenv.2017.11.311.

Lucherini M, Merino MJ. 2008. Perceptions of human-carnivore conflicts in the high Andes of Argentina. Mt Res Dev 28: 81-85. DOI: $10.1659 / \mathrm{mrd} .0903$

Luiselli L. 2001. The ghost of a recent invasion in the reduced feeding rates of spitting cobras during the dry season in a rainforest region of tropical Africa? Acta Oecologica 22: 311-314. DOI: 10.1016/S1146609X(01)01113-4.

Magle SB, Hunt VM, Vernon M, Crooks KR. 2012. Urban wildlife research: past, present, and future. Biol Conserv 155: 23-32. DOI: 10.1016/j.biocon.2012.06.018.

Mallon DP, Hoffmann M, Grainger MJ, Hibert F, Van Vliet N, Mcgowan PJK. 2015. An IUCN situation analysis of terrestrial and freshwater fauna in West and Central Africa. Occasional paper of the IUCN species survival commission, 54, Gland. DOI: 10.2305/IUCN.CH.2015.SSC-OP.54.en.

Marešová J, Frynta D. 2008. Noah's Ark is full of common species attractive to humans: The case of boid snakes in zoos. Ecol Econ 64: 554-558. DOI: 10.1016/j.ecolecon.2007.03.012.

Miranda EB, Ribeiro RP Jr., Strüssmann C. 2016. The ecology of humananaconda conflict: A study using internet videos. Trop Conserv Sci 9: 43-77. DOI: $10.1177 / 194008291600900105$

Molesworth AM, Harrison R, David R, Theakston G, Lalloo DG. 2003. Geographic information system mapping of snakebite incidence in northern Ghana and Nigeria using environmental indicators: a preliminary study. Trans R Soc Trop Med Hygiene 97: 188-192. DOI: 10.1016/S0035-9203(03)90115-5.

Morgan JM, Gramann JH. 1989. Predicting the effectiveness of wildlife education programs: A study of students' attitudes and knowledge toward snakes. Wildlife Society Bulletin 17: 501-509.

Pandey DP, Pandey GS, Devkota K, Goode M. 2016. Public perceptions of snakes and snakebite management: implications for conservation and human health in southern Nepal. J Ethnobiol Ethnomed 12 (1): 22. DOI: 10.1186/s13002-016-0092-0.

Pinheiro LT, Rodrigues JFM, Borges-Nojosa DM. 2016. Formal education, previous interaction, and perception influence the attitudes of people toward the conservation of snakes in a large urban center of northeastern Brazil. J Ethnobiol Ethnomed 12 (1): 25 . DOI: 10.1186/s13002-016-0096-9. 
Prendergast JR, Quinn RM, Lawton JH. 1999. The gaps between theory and practice in selecting nature reserves. Conserv Biol 13: 484-492. DOI: $10.1046 /$ j.1523-1739.1999.97428.x.

Prokop P, and Randler C. 2018. Biological predispositions and individual differences in human attitudes toward animals. 447-466 In: Alves RRN, Albuquerque UP. (eds). Ethnozoology: Animals in Our Lives, 1 st ed. Academic Press, Cambridge, MA. DOI: 10.1016/B978-0-12809913-1.00023-5.

Prokop P, Fančovičová J, Kučerová A. 2018. Aposematic colouration does not explain fear of snakes in humans. J Ethol 36: 35-41. DOI: 10.1007/s10164-017-0533-9.

Prokop P, Fančovičová J. 2010. Perceived body condition is associated with fear of a large carnivore predator in humans. Annales Zoologici Fennici 47: 417-425. DOI: 10.5735/086.047.0606.

Prokop P, Fančovičová J. 2013. Does color matter? The influence of animal warning coloration on human emotions and willingness to protect them. Anim Conserv 16: 458-466. DOI: 10.1111/acv.12014.

Prokop P, Özel M, Uşak M. 2009. Cross-cultural comparison of student attitudes toward snakes. Soc Anim 17: 224-240. DOI $10.1163 / 156853009$ X445398.

Purkayastha J, Das M, Sengupta S. 2011. Urban herpetofauna: a case study in Guwahati City of Assam, India. Herpetol Notes 4: 195-202.

Pyron RA, Burbrink FT, Wiens JJ. 2013. A phylogeny and revised classification of Squamata, including 4161 species of lizards and snakes. BMC Evol Biol 13: 93. DOI: 10.1186/1471-2148-13-93.

Pyron RA, Burbrink FT. 2012. Extinction, ecological opportunity, and the origins of global snake diversity. Evolution 66: 163-178. DOI: 10.1111/j.1558-5646.2011.01437.x.

Rastogi A, Hickey GM, Badola R, Hussain SA. 2013. Diverging viewpoints on tiger conservation: A Q-method study and survey of conservation professionals in India. Biol Conserv 161: 182-192. DOI: 10.1016/j.biocon.2013.03.013.

Reading CJ, Luiselli LM, Akani GC, Bonnet X, Amori G, Ballouard JM, Filippi E, Naulleau G, Pearson D, Rugiero L. 2010. Are snake populations in widespread decline? Biol Lett 6: 777-780. DOI $10.1098 / \mathrm{rsbl} .2010 .0373$

Rim-Rukeh A, Irerhievwie G, Agbozu IE. 2013. Traditional beliefs and conservation of natural resources: Evidence from selected communities in Delta State, Nigeria. Intl J Biodiv Conserv 5: 426432.

Root TL, Price JT, Hall KR, Schneider SH, Rosenzweig C, Pounds JA 2003. Fingerprints of global warming on wild animals and plants. Nature 421: 57. DOI: 10.1038/nature01333.

Røskaft E, Bjerke T, Kaltenborn BP, Linnell JDC, Andersen R. 2003. Patterns of self-reported fear towards large carnivores among the Norwegian public. Evol Human Behav 24: 184-198. DOI: 10.1016/S1090-5138(03)00011-4.
Sani UM, Jiya NM, Ibitoye PK, Ahmad MM. 2013. Presentation and outcome of snakebite among children in Sokoto, North-Western Nigeria. Sahel Med J 16: 148. DOI: 10.4103/1118-8561.125557.

Sasaki K, Sasaki Y, Fox S. 2010. Endangered traditional beliefs in Japan: influences on snake conservation. Herpetol Conserv Biol 5: 474-485

Seigel RA, Mullin SJ. 2009. Snake conservation, present, and future. Pp 281-290 In: Seigel RA, Mullin SJ (eds). Snakes, Ecology, and Conservation. Cornell University Press, Ithaca, New York, USA. DOI: 10.7591/9780801459092-015.

Shine R, Bonnet X. 2000. Snakes: a new 'model organism' in ecological research?. Trends Ecol Evol 15: 221-222. DOI: 10.1016/S01695347(00)01853-X.

Snyder, NF, Derrickson SR, Beissinger SR, Wiley JW, Smith TB, Toone WD, Miller B. 1996. Limitations of captive breeding in endangered species recovery. Conserv Biol 10: 338-348. DOI: 10.1046/j.15231739.1996.10020338.x.

Soewu DA. 2008. Wild animals in ethnozoological practices among the Yorubas of southwestern Nigeria and the implications for biodiversity conservation. Afr J Agric Res 3: 421-427.

Treves A., and K.U. Karanth. 2003. Human-carnivore conflict and perspectives on carnivore management worldwide. Conserv Biol 17: 1491-1499. DOI: 10.1111/j.1523-1739.2003.00059.x.

Trouwborst A, Blackmore A, Boitani L, Bowman M, Caddell R, Chapron G, Cliquet A, Couzens E, Epstein Y, Fernández-Galiano E, Fleurke FM. 2017. International wildlife law: understanding and enhancing its role in conservation. BioScience 67: 784-790. DOI: 10.1093/biosci/bix086.

Uetz P, Hallermann J, Hosek J. 2017. The Reptile Database, 2017. http://www.reptile-database.org/.

Veríssimo D, Vaughan G, Ridout M, Waterman C, Macmillan D, Smith RJ. 2017. Increased conservation marketing effort has major fundraising benefits for even the least popular species. Biol Conserv 211: 95-101. DOI: 10.1016/j.biocon.2017.04.018.

Wallach V, Williams KL, Boundy J. 2014. Snakes of the World: A Catalogue of Living and Extinct Species. CRC Press, FL. DOI: 10.1201/b16901.

Walther JB. 2002. Research ethics in Internet-enabled research: Human subjects issues and methodological myopia. Ethics Inform Technol 4: 205-216. DOI: 10.1023/A:1021368426115.

Whitaker PB, Shine R. 1999. When, where, and why do people encounter Australian brown snakes (Pseudonaja textilis: Elapidae)? Wildlife Res 26: 675-688. DOI: 10.1071/WR98043.

Willson JD, Winne CT. 2016. Evaluating the functional importance of secretive species: A case study of aquatic snake predators in isolated wetlands. J Zool 298: 266-273. DOI: 10.1111/jzo.12311.

Yasuda M, Kawakami K. 2002. The new method of monitoring remote wildlife via the Internet. Ecol Res 17: 119-124. DOI: 10.1046/j.14401703.2002.00467.x 